\title{
Serious Game Relationship Between Socio-Economic and Territorial Condition
}

\author{
Windi E.Y. Retnani, Saiful Bukhori* \\ Research Group of Data and Business Intelligence, Department of Computer Science, University of Jember, Jember 68121, \\ Indonesia
}

Corresponding Author Email: saiful.ilkom@unej.ac.id

https://doi.org/10.18280/mmep.080107

Received: 29 December 2019

Accepted: 12 December 2020

\section{Keywords:}

sustainable development, internal factor variables, external factor variables, supply, demand

\begin{abstract}
This research models a sustainable development through a serious game. The sustainable development system is influenced by internal factors and external factors. Internal factors consist of three sub-systems, namely: Culture, structure and technology. External factors consist of three sub-systems, namely: environment, economic actors and socio-cultural actors. The model in this research is agent-based involving three types of agents (firm, worker, and policy), internal variables, and external variables using a dynamic system. The behavior of each variable is observed using a dynamic system model. By providing initial values in internal factor variables and external factor variables, agent movement can provide information about the firm-size condition, the income of workers and the effect of policy on the development of companies and workers. Determination of initial data from internal factor variables and external factor variables aims to achieve a balance between supply and demand. In a certain phase, it will produce an optimal value, shown by supply and demand are at the same point. This condition needs to be maintained by adjusting all input variables so that supply and demand are in an optimal position.
\end{abstract}

\section{INTRODUCTION}

Sustainable development is a development goal that involves economic, social, ecological and spatial development. These developments must be complemented each other [1]. Economic, social, ecological and spatial development when simplified involves two main elements, namely: socioeconomic circumstances and the condition of territorial area. This research is modelling the socio-economic circumstances and the condition of territorial area through a serious game.

The implementation of a society sustainable development strategy is currently under debate. The closure of mining companies in the mining area with high ecological problems would normally leave the social, environmental and economic problem. For a new approach to sustainability with maximum efficiency, in line with the policies adopted by the government, new strategic thinking is needed that combines regional issues and accelerates the process of alignment with global requirements [2].

This research is proposing an objective analysis of the main socio-economic situations that occurred in the previous years, there is a proposed strategy for conducting public management. In addition, this research also examines the territorial dimensions of sustainable development areas and recommends an integrative model that suits current needs by adopting an agent-based model and dynamic systems.

Several researches have succeeded in adopting agent-based model. Crisis simulation for a RTGS is modelled by Luca at al using an agent-based model. This model uses approach the macro-features of reality, shown the sequential effects of an unexpected negative shock affecting [3]. The graph mining to exploring agent-based methods for activity network prediction in RTGS payment system based on clearing house. This research models an activity network in the graph and models the data by entangling variables having an effect on find relationship between banks [4]. The model of activity network system adopts the decentralization paradigm. The principal component of this system are adaptive agents consisting of five agents that are saving agent, reserves agent, loan agent, deposit agent and money transfer agent [5, 6]. Competitive advantage in serious game Supply Chain Management (SCM) Agroindustry by using hybrid forest fire model and profile matching. The focus of this research is adopting an agentbased models in order to fulfil of tobacco from the farmers to cigarette factory [7].

The focus of this research is to analyze the relationship between socio-economic aspects and regional conditions in the sustainable development of a region. Sustainable development is a development in a region that meets the needs of the present without compromising future capabilities [8, 9]. In this research is modeling the conditions of internal factors and conditions of external factors using a dynamic system. The model used in this research is agent-based by involving agent firm, agent worker and agent policy. These agents provide information about the firm-size condition, the income of workers and the effect of policy on the development of companies and workers. Setting initial data from internal factor variables and external factor variables aims to achieve a balance between supply and demand.

The rest of this paper is organized as follows. The proposed model for strategic approach to sustainable development is discussed in section 2. Section 3 gives the analysis of potential district. Finally conclusions are given in section 4 . 


\section{METHODOLOGICAL APPROACH}

The sustainable development of an area puts a people at the center of society, as well as the living environment and its care. Sustainable development is development in an area that meets the needs of the present without compromising the ability of future generations to meet their own [10]. It estimates of what is needed by the society and what will be required of future generations. In addition, the general model of sustainable development shows that there is not an independent factor causing sustainability without a permanent inter-relationship between them, as shown in Figure 1.

Figure 1 shows a model of a sustainable development. This model illustrates that the three main pillars underlying a sustainable development are: economic, socio-cultural, and ecological. These pillars are interdependent and mutually influence. To achieve organizational goals is required a number of indicators that ensure the operational working well. Having determined the indicators, then proceed with determining the criteria as a measurement between zero and the target.

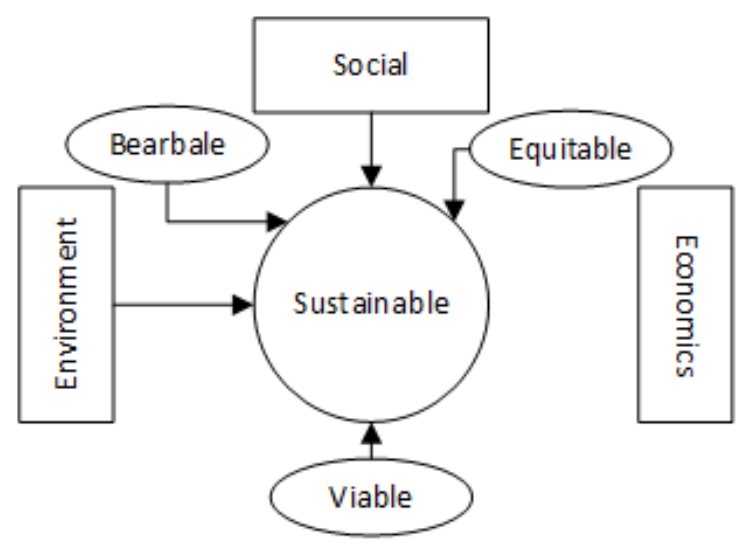

Figure 1. General model of sustainable development

To achieve organizational goals, it is necessary to integrate and balance the three pillars of sustainable development. Therefore, in compiling a balance between these pillars requires bearable, equitable and viable [11]. Bearable is applied between society and environment. Society must make lifestyle adjustments so that it understands the impact of what is done and then tries to contribute to the environment and better welfare. Equitable is implemented in society and economy. Equitable is needed for equal and fair use of resources owned by the state for society. With equality, it is hoped that it can alleviate poverty, social inequality and improve people's lives. Viable applies to economics and the environment. A nation tries to grow and develop its economy but still pay attention to the protection of its environment. Therefore, investment must be able to sustain itself, create jobs, improve people's welfare, and protect the environment from harm.

Sustainable development will lead to major changes in all aspects of life. Models developed World Bank on sustainable development highlights the change of government should be based on technological, cultural and structural change. These factors are interdependent in optimization, improvement and renewal. In each of these approaches, a specific interaction between culture, structure and technology can be recognized as shown in Figure 2. The specific interaction between culture, structure and technology is an environment that can be modeled with agent-based modeling. Agents interact with each other, imitate, communicate, exchange and can also compete with each other $[12,13]$. Based on the heterogeneous interaction modalities, various socialites can produce information including communication, identity, economy and culture.

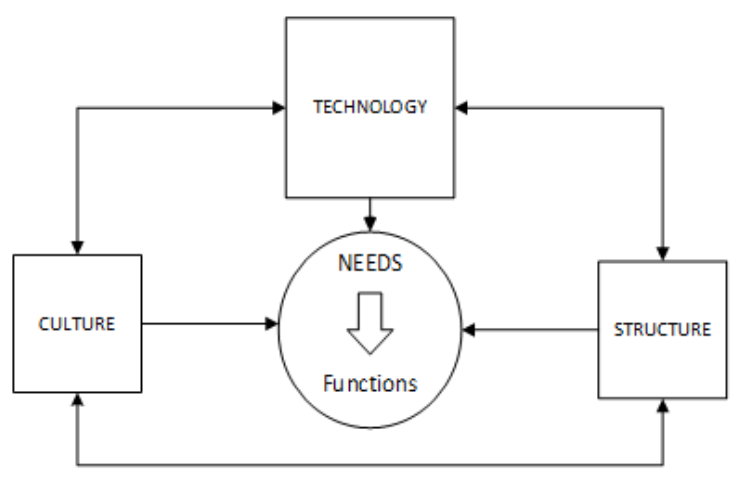

Figure 2. Interaction between culture, structure and technology

A strategic approach in sustainable development, which is modeled using agent-based, must create a social perception that institutions serve the community [14]. Based on these perceptions, the influence of public management which causes changes in society can be an observable model. Public management that causes changes in society is not only influenced by internal variables (culture, structure and technology) but also influenced by external variables as an input such as environment, economic actors, and sociocultural actors as shown in Figure 3.

The dynamic behavior of sustainable development system is largely determined by the structure of the feedback loops formed by each of the variables that influence both variables in internal and external factors. Each variable acts as a subsystem in a closed system [15]. Closed system formed shows the characteristics of the dynamic properties of a system. In dynamic systems more attention directed toward a closed system or the feedback system. This feedback system is a building block model represented by the closed circles. The circumference feedback is stating causality circular variables.

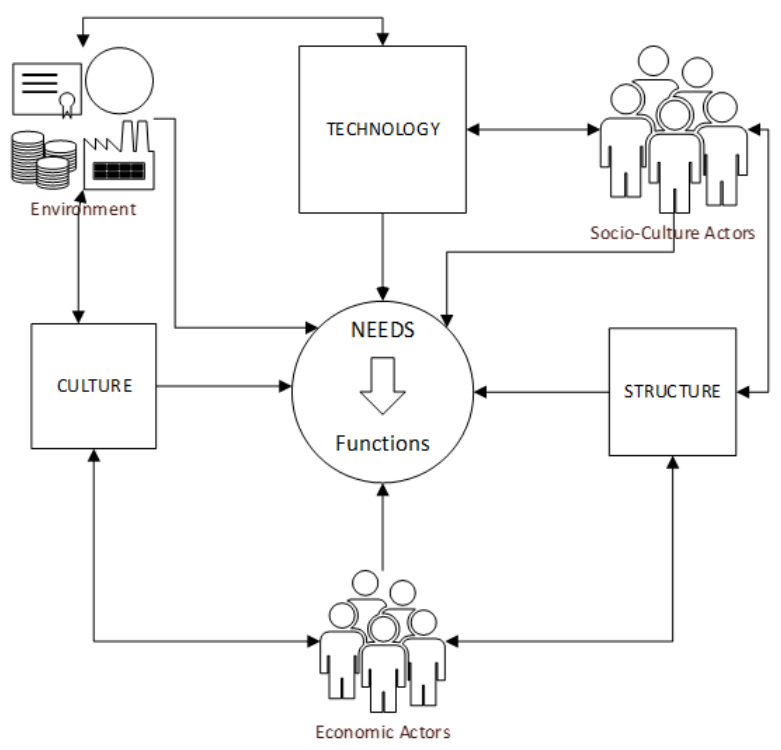

Figure 3. Internal variable and external variable 
Sustainable development system is influenced by Internal Factors (u) and External Factors (y). Internal Factors consist of three sub-systems, namely: Culture, Structure and Technology. External Factors consist of three sub-systems, namely: Environment, Economic Actors and Socio-Culture Actors [16-18]. Each sub-system consists of several variables as shown in Table 1.

The dynamics of each variable behavior was observed in this research using a model of a dynamic system [19-21]. Dynamic system models can be expressed using differential equations. The general form of linear system of order $\mathrm{n}$ can be written by the following equation:

$$
\begin{aligned}
& g\left(y^{(n)}(t), y^{(n-1)}(t), \ldots \ldots, y(t),\right. \\
& u^{(m)}(t), u^{(m-1)}(t), \ldots, u(t)=0
\end{aligned}
$$

And $y^{(k)}(t)$ can be expressed by the following equation,

$$
y^{(k)}(t)=\frac{d^{k}}{d t^{k}} y(t)
$$

Table 1. Internal factors and external factors
The basic concept of a dynamic system that interacts with the system can be expressed using the input variables and output variables. Input variables or more simply referred to as the input is a set of variables that come from outside the system and not directly dependent on events in the system. In this research input variables are external factors (y). Output variable or simply referred to as output a set of variables generated by the sub-systems that exist in the system. In this research, the output variables are internal factors $(u)$.

$$
\begin{aligned}
a_{n} \frac{d^{n} y}{d t^{n}}+a_{n-1}(t) & \frac{d^{n-1}}{d t^{n-1}}+\cdots+a_{1} \frac{d y}{d t}+a_{0} y \\
& =b_{m} \frac{d^{m} u}{d t^{m}}+b_{m-1} \frac{d^{m-1} u}{d t^{m-1}}+\cdots \\
& +b_{1} \frac{d u}{d t}+b_{0} u
\end{aligned}
$$

\begin{tabular}{|c|c|c|c|}
\hline \multicolumn{2}{|c|}{ Internal Variable } & \multicolumn{2}{|r|}{ External Variable } \\
\hline \multirow{3}{*}{ Culture } & Road density & \multirow{4}{*}{ Environment } & River number \\
\hline & Daily shopping & & Lake number \\
\hline & Sub urban housing & & Hill number \\
\hline \multirow{6}{*}{ Structure } & Culture number & & \\
\hline & Policy support & \multirow{4}{*}{$\begin{array}{l}\text { Economic } \\
\text { Actors }\end{array}$} & Initial number firm \\
\hline & Prior area & & Initial number CW \\
\hline & Tax rate & & Base product demand \\
\hline & Mean tenure & & \\
\hline & Clover leaf number & \multirow{7}{*}{$\begin{array}{l}\text { Socio-Cultural } \\
\text { Actors }\end{array}$} & Demand monthly growth rate \\
\hline \multirow{6}{*}{ Technology } & Green park number & & Growth rate cycle \\
\hline & Subway number & & Maximum job hunting \\
\hline & Indor park number & & Maximum time failure finding jobs \\
\hline & University number & & Maximum failure finding office \\
\hline & Old factory number & & Maximum time office searching \\
\hline & Old housing number & & Maximum housing finding \\
\hline
\end{tabular}

\begin{tabular}{|c|c|c|c|}
\hline \multirow{2}{*}{$\begin{array}{c}\text { Internal Variable } \\
\text { Variable }\end{array}$} & \multicolumn{3}{|c|}{ External Variable } \\
\hline & Value & Variable & Value \\
\hline Road density & Medium & River number & 1 \\
\hline Daily shopping & Medium & Lake number & 1 \\
\hline Sub urban housing & & Hill number & 1 \\
\hline Culture number & Medium & & \\
\hline Policy support & Medium & Initial number firm & 30 \\
\hline Prior area & Inner City District & Initial number $\mathrm{CW}$ & 300 \\
\hline Tax rate & $20 \%$ & Base product demand & 115 \\
\hline Mean tenure & 60 & & \\
\hline Clover leaf number & Medium & Demand monthly growth rate & 0.01 \\
\hline Green park number & Medium & Growth rate cycle & 0 \\
\hline Subway number & Low & Maximum job hunting & 30 \\
\hline Indor park number & Medium & Maximum time failure finding jobs & 6 \\
\hline University number & Medium & Maximum failure finding office & 6 \\
\hline Old factory number & Medium & Maximum time office searching & 10 \\
\hline Old housing number & Medium & Maximum housing finding & 200 \\
\hline
\end{tabular}

$a_{0}, a_{1}, \ldots, a_{n}$ and $b_{0}, b_{1}, \ldots, b_{m}$ are constants

Table 2. Initial data of internal factors and external factors

\section{CONDUCTING RESEARCH AND RESULTS}

This research starts with define the initial data of each input variables and output variables. Input variables and output variables are determined as shown in Table 2. Based on these initial data are observed the dynamic conditions from the firm, income of the workers, comparison of the firm, workers and influence of the policies, development of residents condition (agent) who do not have the job, not have home and not have land from time to time and the latter observing the supply and demand of the potential district.

Based on the initial data conditions that are determined as 
shown in Table 2, the dynamic development of the firm condition can be mapped to companies with development at a rapid pace ( $\max )$, the company with the development in the medium (median) and the company's less developed (min). Based on the Figure 4, shows that the firm-size-max develop very high but fluctuate. Firm-size-medium and firm-size-min develop slowly but tend to rise. So based on this condition, the standard deviation and the mean of the firm development looks likely to rise slowly but tend to rise.

Income conditions of the worker follows the pattern of the firm. Income from high worker $(\max )$ tends to fluctuate at certain times rise, while others go down. Income condition of the median worker and min worker tend to remain despite ups and downs but not too high. Figure 5 represents the income of workers.

Development of the firm and workers are not always significant. Figure 6 show without the influence of government policy, Development of the firm tend to be faster than development of the workers. However, at certain times development of the firm started to decline and follow the development of workers.

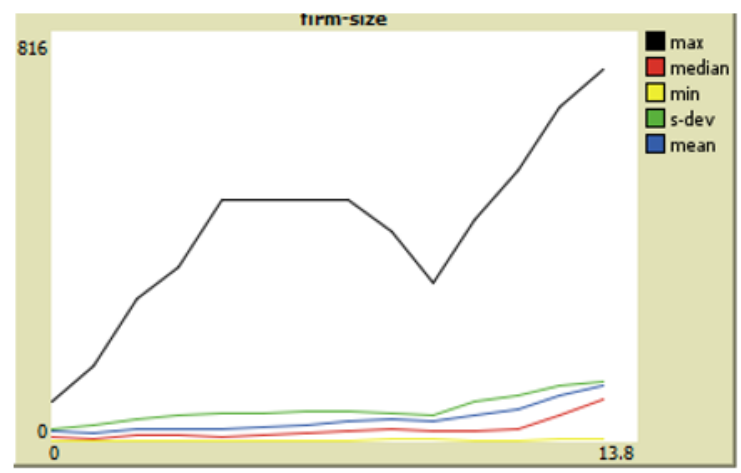

Figure 4. Firm-size condition

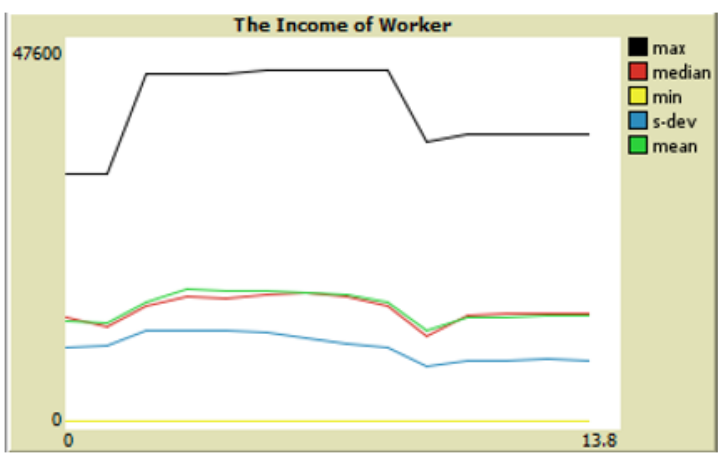

Figure 5. The income of worker

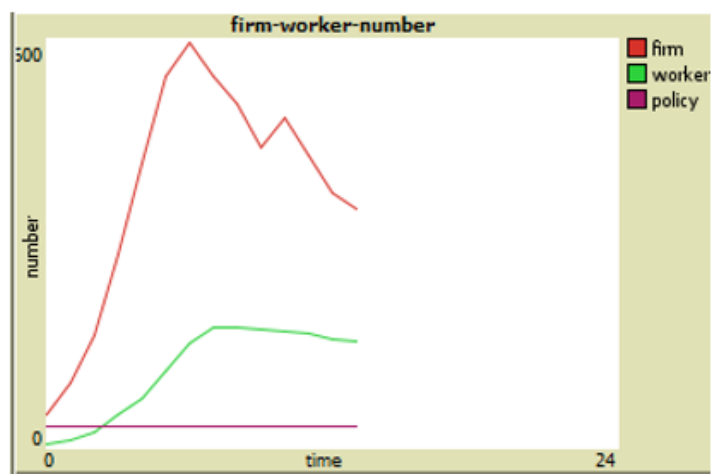

Figure 6. The effect of policy on the development of companies and workers
To optimize firm growth and job growth is needed to set a policy that not only benefit the company which is the stronger side, but it should also draw up policies that benefit workers who are the weaker party.

Conditions of the community (agent) to note is not having a job. In Figure 7 is seen that the initial conditions as shown in Table 2, the problem has no home and no land are not a major problem but the condition of the community who are no job are a great impact although at a specific phase will decrease and at some point toward a fixed value.

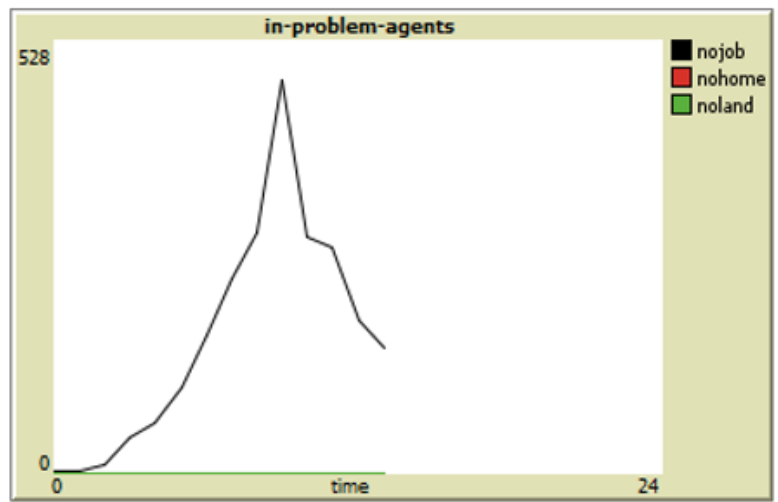

Figure 7. The problem of the community (agent)

In the final stage is the analysis of supply and demand. Determination of the initial data from the Internal Factors and External Factors are aiming to achieve a balance between supply and demand. Initial data conditions as shown in Table 2 resulted in supply and demand as shown in Figure 8. In Figure 8 is shown that the value of the initial supply should be increased to get an optimal values. At a certain phase will produce the optimal value where supply and demand at the same point. These conditions need to be maintained by adjusting all input variables so that supply and demand are in the optimal position.

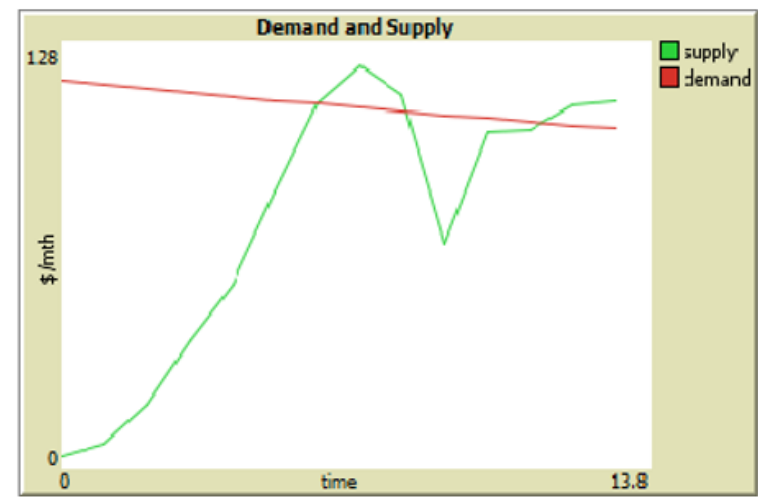

Figure 8. Supply and Demand

\section{CONCLUSION}

Sustainable development system is influenced by internal factor and External Factor. Internal factors consist of three sub-systems, namely: Culture, Structure and Technology. External factors consist of three sub-systems, namely: Environment, Actor Economic and Socio-cultural dynamics Actors. Internal factors and external factors are interdependent and form a dynamic system. The sustainable development system behavior is determined by the structure of the feedback 
loop formed by each of the variables that influence. The management process of the sustainable development requires determination of the initial conditions value from the internal factors variables and external factors variables.

The dynamic development of the firm condition can be mapped to firm's with development at a rapid pace (max), the firm's with the development in the medium (median) and the firm's less developed (min). The development of the firm in a district is determined by the initial variable conditions of the internal factors and external factors. Developments in income conditions of the worker tend to follow the pattern of development of the firm.

Development of the firm and workers are not always significant. To manage the development of the firm and workers in order to balance is required the government policy. The government policy in addition to balancing the development of the firm and workers as well as to solve the problems of the impact of people who are not working

Determination of the initial data from the Internal Factors and External Factors are aiming to achieve a balance between supply and demand. At a certain phase will produce the optimal value where supply and demand at the same point. These conditions need to be maintained by adjusting all input variables so that supply and demand are in the optimal position.

\section{REFERENCES}

[1] Zielinska, A. (2011). Applying multidimentional comparative analysis for the assessment of the concept realization of sustainable development for the protected areas. Economics \& Sociology, 4(1): 87 https://doi.org/10.14254/2071-789X.2011/4-1/9

[2] Rutkauskas, A.V., Raudeliuniene, J., Racinskaja, I. (2014). Integral knowledge, innovation and technology cluster formation nurturing the universal development sustainability in the context of globalization. Economics \& Sociology, 7(4): 41. https://doi.org/10.14254/2071789X.2014/7-4/3

[3] Arciero, L., Biancotti, C., d'Aurizio, L., Impenna, C. (2008). Exploring agent-based methods for the analysis of payment systems: A crisis model for StarLogo TNG. Bank of Italy Temi di Discussione (Working Paper) No, 686. https://doi.org/10.2139/ssrn. 1290520

[4] Bukhori, S., Hariadi, M., Purnama, I.K.E., Purnomo, M.H. (2009). Exploring agent-based methods for activity netework prediction in real time gross settlement (RTGS) based on clearing house. IJCSNS International Journal of Computer Science and Network Security, 9(11): 121-128.

[5] Bukhori, S., Moch Hariadi, I. (2016). Intelligent agent for serious game of real time gross settlement using forest fire model. Journal of Theoretical and Applied Information Technology, 25(2): 79-87.

[6] Bukhori, S., Hariadi, M., Purnama, I.K.E., Purnomo, M.H. (2016). Parrondo's paradox based strategies in the serious game of RTGS using forest fire model.

[7] Bukhori, S., Utami, W., Slamin, S. (2016). Hybrid profile matching and forest fire model strategies in serious game supply chain management agribusiness. International Journal of Supply Chain Management, 5(3): 25-31.

[8] Gebetsroither-Geringer, E. (2014). Multimethod modeling and simulation supporting urban planning decisions. In Understanding complex urban systems: Multidisciplinary Approaches to Modeling, 13-27. https://doi.org/10.1007/978-3-319-02996-2

[9] Retnani, W.E.Y., Bukhori, S. (2017). Optimation of the agricultural land with potential mapping based on the characteristics of the land. Advanced Science Letters, 23(3): 2348-2350. https://doi.org/10.1166/asl.2017.8763

[10] Daft, R.L. (2010). Organization Theory and Design, 10th ed. South-Western Cengage Learning, 2010.

[11] Mensah, J., Casadevall, S.R. (2019). Sustainable development: Meaning, history, principles, pillars, and implications for human action: Literature review. Cogent Social Sciences, 5(1): 1653531. https://doi.org/10.1080/23311886.2019.1653531

[12] Lippert, A., Shubeck, K., Morgan, B., Hampton, A., Graesser, A. (2019). Multiple agent designs in conversational intelligent tutoring systems. Technology, Knowledge and Learning, 1-21. https://doi.org/10.1007/s10758-019-09431-8

[13] Cho, S., Knapen, L., Bellemans, T., Janssens, D., Wets, G. (2012). A conceptual design of an agent-based interaction model for the carpooling application. Procedia Computer Science, 10: 801-807. https://doi.org/10.1016/j.procs.2012.06.103

[14] Rădulescu, C., Toader, R., Boca, G., Abrudan, M., Anghel, C., Toader, D.C. (2015). Sustainable development in maramures county. Sustainability, 7(6): 7622-7643. https://doi.org/10.3390/su7067622

[15] Uehara, T., Cordier, M., Hamaide, B. (2018). Fully dynamic input-output/system dynamics modeling for ecological-economic system analysis. Sustainability, 10(6): 1765. https://doi.org/10.3390/su10061765

[16] Sun, L., Yu, X., Li, B., Zhang, H., Sha, D., Wang, Y., Yu, R. (2020). Coupling analysis of the major impact on sustainable development of the typical arid region of Turpan in Northwest China. Regional Sustainability, 1(1): 48-58. https://doi.org/10.1016/j.regsus.2020.08.002.

[17] Reyers, B., Stafford-Smith, M., Erb, K.H., Scholes, R.J., Selomane, O. (2017). Essential variables help to focus sustainable development goals monitoring. Current Opinion in Environmental Sustainability, 26: 97-105. https://doi.org/10.1016/j.cosust.2017.05.003

[18] Dong, J., Liu, D., Wang, D., Zhang, Q. (2019). Identification of key influencing factors of sustainable development for traditional power generation groups in a market by applying an extended MCDM model. Sustainability, $11(6)$ : https://doi.org/10.3390/su11061754

[19] Ciampi, G., Rosato, A., Sibilio, S. (2016). Dynamic simulation of a micro-trigeneration system serving an Italian multi-family house: Energy, environmental and economic analyses. International Journal of Heat and Technology, 34(2): S295-S302. https://doi.org/10.18280/ijht.34sp0215

[20] Sun, S., Lei, G., Sun, Z. (2019). Dynamic and Static Load Tests on a Large-span Rigid-frame Bridge Dynamic and Static Load Tests on a Large-span Rigid-frame Bridge. https://doi.org/10.18280/mmep.060312

[21] Rowell, D. (2002). State-space representation of LTI systems.

URL: http://web.mit.edu/2.14/www/Handouts/StateSpace. pdf. 